\title{
Evaluation of ultrasonic-assisted dyeing properties of fast-growing poplar wood treated by reactive dye based on grey system theory analysis
}

\author{
Xiaoqian Wang ${ }^{1} \cdot$ Zhiming Yu$^{1} \cdot$ Yang Zhang ${ }^{1} \cdot$ Chusheng $\mathbf{Q i}^{1} \cdot$ Wen-lung Chang ${ }^{2}$
}

Received: 7 June 2018 / Accepted: 12 September 2018 / Published online: 1 November 2018

(c) The Japan Wood Research Society 2018

\begin{abstract}
Ultrasonic-assisted dyeing as a novel and eco-friendly method was utilized to improve decorative value of fast-growing tree species. The effects of ultrasonic-assisted dyeing parameters (e.g., temperature, dye concentration, ultrasonic power, dipping time, dyeing assistant and dye-fixing agent) on the properties of wood were investigated, and the parameters were optimized. Moreover, the main factors mentioned above were determined with grey system theory analysis. Analyses of chemical structure, thermostability, crystallinity, and microscopic morphologies were conducted using fourier transform infrared spectroscopy (FTIR), thermogravimetric (TG), X-ray diffraction (XRD), and scanning electron microscope (SEM), respectively. Results showed that dye uptake and $K / S$ were influenced by the parameters in the following order: dye concentration $>$ dye-fixing agent $>$ dyeing assistant $>$ dipping time $>$ ultrasonic power $>$ temperature. FTIR indicated that an ether bond was formed between the wood component and the reactive dye. TG and XRD demonstrated that the thermal stability and crystallinity of ultrasonic-assisted dyed wood were both improved. SEM revealed that dye molecules diffused into the cell cavity, wood vessel, aperture, and part of the wood microstructure such as pit membrane, which was mechanically damaged after the ultrasonic-assisted dyeing treatment and created new fluid channels for the dye.
\end{abstract}

Keywords Ultrasonic-assisted dyeing $\cdot$ Reactive dye $\cdot$ Grey system theory analysis $\cdot$ Dye uptake $\cdot K / S$

\section{Introduction}

With the decreasing supply of precious wood over the past few decades, fast-growing plantation wood has been widely regarded as an alternative due to its short growth cycle, good permeability, and moderate prices $[1,2]$. However, the tone is relatively bland, and the superficial color is variational, which leads to the reduced aesthetic value for fast-growing wood. Wood dyeing, an advanced and mature technique, can eliminate color differences, simulate the color properties of

Zhiming Yu

yuzhiming@bjfu.edu.cn

Yang Zhang

bjfuzhangyang@bjfu.edu.cn

1 MOE Key Laboratory of Wooden Material Science and Application, Beijing Forestry University, Qinghua East Road 35, P. O. Box 734, Beijing 100083, China

2 Chemistry Department, University of Idaho, 875 Perimeter Drive MS 1132, Moscow, ID 83844-1132, USA highly valuable wood species, and improve the visual characteristics of wood products [3, 4]. The dyed wood products have been widely applied in furniture, flooring, interior decoration, and sports equipment, etc., and generated tremendous social and economic benefits [5-7].

Atmospheric pressure impregnation, a simple and mature technique, is the common method for wood dyeing. However, the dyeing process is usually energy-intensive and time-consuming [8]. In addition, the low utilization rate of dyestuff gives rise to high cost and environmental pollution. Because of the poor wood permeability, it is more difficult for dyestuff to penetrate wood with increasing wood veneer's thickness. Therefore, the conventional method only applies to dyeing thin wood veneers $(<0.7 \mathrm{~mm})$ [9]. In dyeing process, the aim is to diffuse and immobilize dyestuff into wood fiber, which plays a vital role in dye uptake, color strength, and dyed wood product quality. However, the available channels for dyestuff to penetrate wood are limited [10]. Thus, there is a growing demand of eco-friendly and energy-efficient dyeing method for thick wood veneers. 
Ultrasonic dyeing technique has been widely adopted to decrease energy consumption and increase productivity in textile dyeing industry [11]. Ultrasonic energy can homogenize chemicals and accelerate both physical and chemical reactions, mainly due to the cavitation in a liquid medium $[12,13]$. Cavitation phenomenon is formation, growth and collapse of microscopic bubbles [14]. Sudden implosion of the cavitational bubbles can generate "hot spots", such as localized high temperature, high pressure, shock waves and severe shear force capable of breaking chemical bonds [15]. The special mechanical and thermal effect can decrease the particle size of dyestuff, make dye solution more homogeneous, and increase its solubility [16]. Ultrasound-assisted dyeing treatment not only increases dye uptake, but also reduces the dosage of dyestuff, and lowers the required temperature or time $[17,18]$. More importantly, application of ultrasonic energy in dyeing can improve environment by reduced consumption of auxiliary chemicals, and lower overall processing cost [19, 20].

Recently, ultrasonic treatments have been used to improve wood permeability, such as in the aspects of wood drying, extraction, and impregnation by some researchers [21-24]. However, there are only a handful of studies on the application of ultrasonic-assisted wood dyeing. Sun and $\mathrm{Yu}$ [6] investigated the ultrasonic effects on dye uptake using poplar wood veneers and acidic dyes as raw materials, and found that ultrasound increased dye uptake under optimal conditions. Liu et al. [3] studied the properties of dyed poplar wood with acid red GR dye using ultrasonicassisted treatment and concluded that dye uptake, chromatic value and wood permeability were improved. Nevertheless, the acid dyes used in their researches permeated the wood without any chemical reaction, which resulted in dye running off easily from the wood. Furthermore, very few studies have been concerned with dyeing mechanisms with ultrasonic-assisted treatment.

In this work, we aimed to investigate the dyeing effects of reactive dye on fast-growing poplar wood veneer with ultrasonic-assisted treatment. More importantly, the bonding mechanisms of dye with wood were studied. Also explored were effects of ultrasonic power, temperature, dye concentration, dipping time, the dosage of dyeing assistant and dye-fixing agent on dye uptake and color strength. The significant influence factors for dyeing wood were analyzed with grey system theory. The chemical structure, thermostability, crystalline, and microcosmic morphography of dyed wood veneer were also evaluated using fourier transform infrared spectroscopy (FTIR), thermogravimetric (TG), X-ray diffraction (XRD), and scanning electron microscope (SEM). This work may help provide a theoretical basis for wood dyeing using reactive dye with ultrasonic-assisted treatment.

\section{Materials and methods}

\section{Materials}

Defect-free fast-growing poplar boards of P. tomentosa Carr. (sapwood) were chosen and conditioned to $10 \%$ equilibrium moisture content. The veneer sample dimensions were $100 \mathrm{~mm} \times 100 \mathrm{~mm} \times 1.0 \mathrm{~mm}$. Reactive Brilliant Blue KN-R (C.I. Reactive Blue 19), which belongs to beta sulphuric acid esters of hydroxyethyl sulfone reactive dye commonly used in textile dyeing, was provided by Taopu Dye Plant in Shanghai, China. Sodium chloride, sodium carbonate, sodium silicate and hydrogen peroxide $\left(\mathrm{H}_{2} \mathrm{O}_{2}\right)$ were of analytical grade and provided by Yi Xiu Bo Gu Company (China). The molecular structure of Reactive Brilliant Blue $\mathrm{KN}-\mathrm{R}$ is shown in Fig. 1.

\section{Bleaching treatment}

The wood samples were bleached to even in tone. The bleached wood samples were prepared at a water bath temperature of $60^{\circ} \mathrm{C}$, a $30 \%(\mathrm{v} / \mathrm{v}) \mathrm{H}_{2} \mathrm{O}_{2}$ concentration of $3.0 \%$, with sodium silicate of $5.0 \mathrm{~g} / \mathrm{L}$, a treating time of $75 \mathrm{~min}$ and a volume ratio of 1:20.

\section{Dyeing method}

A ultrasonic-assisted dip-dye method at atmospheric pressure was used for veneer dyeing. Wood veneers were vertically immersed in the dye solution, leaving sufficient space between each veneer so as to ensure the maximization of ultrasonic wave obtained per unit area of the dyeing veneers. A volume ratio of 1:20 $\left(V_{\text {veneer }}: V_{\text {solution }}\right)$ was maintained throughout the experiment. The solution was stirred every $15 \mathrm{~min}$ for even penetration. After dyeing, the treated wood samples were rinsed thoroughly with distilled water to wash away the residual dye, and then air-dried to $8 \%$ moisture

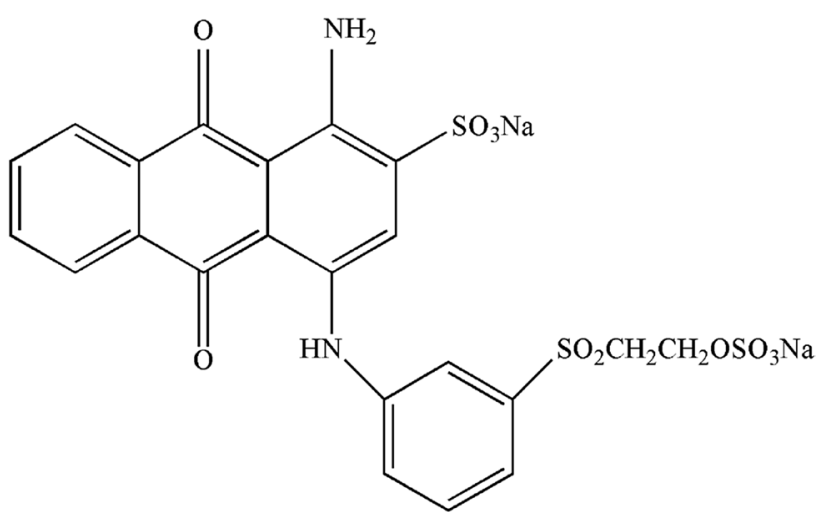

Fig. 1 Chemical structure of Reactive Brilliant Blue KN-R 
content without light. The reaction mechanism of dye and wood is shown in Fig. 2.

Associated single experimental factors are shown in Table 1.

\section{Characterization}

\section{Measurement of dye uptake}

Dye uptake was characterized by absorption of dye from dye bath to wood samples. A UV-visible spectroscopy (721 ApL, China), which found a maximum absorption wavelength $\left(\lambda_{\max }\right)$ for Reactive Brilliant Blue KN-R dye at $598 \mathrm{~nm}$, was used to determine the absorption. Dye uptake was calculated based on the following equation [25]:

$C_{\mathrm{t}}(\%)=\frac{A_{0}-A_{\mathrm{t}}}{A_{0}} \times 100$,

where $A_{0}$ and $A_{\mathrm{t}}$ are the absorption of the dye solution at $\lambda_{\max }$ before and after wood dyeing, respectively.

\section{Measurement of color}

The $K / S$ values were assessed for the dyed wood veneer samples, which determines the color strength of dyed wood by using a color measuring instrument (Dataflash 110 Datacolor, USA) with illumination/observer conditions set at $\mathrm{D} 65 / 10^{\circ} . \mathrm{K} / \mathrm{S}$ values were calculated from reflectance values using the Kubelka-Munk equation [26],

$K / S=\frac{(1-R)^{2}}{2 R}$

where $K$ is the absorption coefficient, $S$ is the scattering coefficient, and $R$ is the decimal fraction of the reflectance of the dyed wood.

\section{Fourier transform infrared spectroscopy (FTIR) analysis}

Fourier transform infrared spectroscopy (Nicolet 6700, Thermo Scientific, USA) was used to analyze the surface chemical structure of the dyed and undyed wood samples. The samples were ground to 200-mesh size and embedded

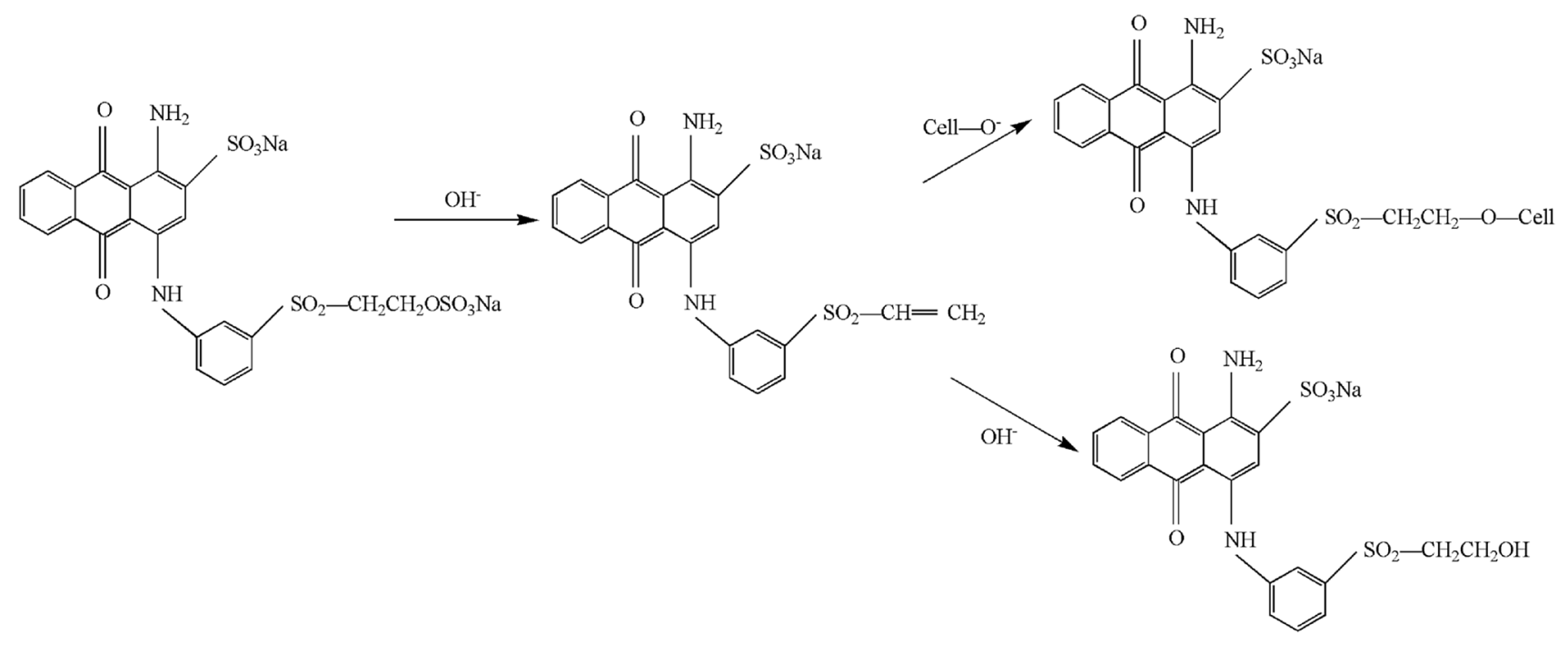

Fig. 2 The reaction mechanism of Reactive Brilliant Blue KN-R dye and wood

Table 1 Single-factor experimental conditions for dyeing poplar wood

\begin{tabular}{|c|c|c|c|c|c|}
\hline Temperature $\left({ }^{\circ} \mathrm{C}\right)$ & Dye concentration (\%) & Ultrasonic power $(\mathrm{W})$ & Dipping time (min) & Dyeing assistant $(\mathrm{g} / \mathrm{L})$ & Dye-fixing agent $(\mathrm{g} / \mathrm{L})$ \\
\hline $20,30,40,50,60,70$ & 0.1 & 200 & 120 & 20 & 15 \\
\hline 40 & $0.1,0.3,0.5,1.0,2.0$ & 200 & 120 & 20 & 15 \\
\hline 40 & 0.1 & $0,80,120,160,200$ & 120 & 20 & 15 \\
\hline 40 & 0.1 & 200 & $30,60,90,120,180$ & 20 & 15 \\
\hline 40 & 0.1 & 200 & 120 & $10,20,30,40,50$ & 15 \\
\hline 40 & 0.1 & 200 & 120 & 20 & $10,15,20,25,30,40$ \\
\hline
\end{tabular}


into potassium bromide $(\mathrm{KBr})$ pellets. The pellets were subjected to FTIR spectrophotometry in the range of $4000-400 \mathrm{~cm}^{-1}$ and at a resolution of $4 \mathrm{~cm}^{-1}$ for 32 scans.

\section{Thermogravimetric (TG) analysis}

The thermal decomposition studies of the samples were carried out using a Q5000 TGA analyzer (TA Instruments, USA). Approximately 4-6 mg of sample was heated from room temperature to $600{ }^{\circ} \mathrm{C}$ at a heating rate of $10 \% \mathrm{~min}$ under nitrogen atmosphere $(100 \mathrm{~mL} / \mathrm{min})$.

\section{X-ray diffraction (XRD) analysis}

The crystallinity of the dyed and undyed wood samples was evaluated using an XRD instrument: D8 advance diffractometer (Brüker, USA) equipped with a $\mathrm{Cu} \mathrm{K} \alpha$ radiation source $(\lambda=0.154 \mathrm{~nm})$. A $2 \theta$ range between $5^{\circ}$ and $50^{\circ}$ was scanned with a $0.02^{\circ}$ step and a scan speed of $2 \% \mathrm{~min}$. The crystallinity was measured as the ratio of the intensity difference in the selected peak positions.

The crystallinity index $(C I)$ for wood samples was determined by the following equation:

$C I(\%)=\left(I_{\mathrm{Max}}-I_{\mathrm{Am}}\right) / I_{\mathrm{Max}} \times 100$,

where $I_{\mathrm{Max}}$ is the maximum intensity of the lattice diffraction peak, and $I_{\mathrm{Am}}$ is the intensity scattered by the amorphous fraction of the sample.

\section{Scanning electron microscopy (SEM) analysis}

The distribution of reactive dye molecules in wood cells were detected with SEM (Hitachi S-3400N, Japan) at an accelerating voltage of $15 \mathrm{kV}$. The tangential sections of the samples were fixed on conductive adhesives and then coated with gold.

\section{Grey system theory analysis}

Grey system theory analysis is a system engineering discipline based on the mathematical theory. It can be widely applied to various fields, such as agriculture, geology and weather. According to the grey system theory analysis, the results of qualitative analysis and quantitative analysis are always consistent. In this study, we can determine which factors influence the dye uptake and $K / S$ the most by using grey system theory analysis.

It is assumed that,

$Y_{1}, Y_{2}, \ldots, Y_{s}$ are the systematic characteristics behavior sequences, and $X_{1}, X_{2}, \ldots, X_{m}$ are the correlation factor behavior sequences. Moreover, $Y_{i}=\left(y_{i}(1), y_{i}(2), y_{i}(3), \ldots\right.$, $\left.y_{i}(n)\right), X_{j}=\left(x_{j}(1), x_{j}(2), x_{j}(3), \ldots, x_{j}(n)\right)$, and the length of $Y_{i}(i=1,2, \ldots, s)$ and $X_{j}(j=1,2, \ldots, m)$ is equal. $\varepsilon_{i j}$ is the gray absolute correlation degree of $Y_{i}$ and $X_{j}$. Then, the gray absolute correlation matrix can be defined as follows:

$A=\left(\varepsilon_{i j}\right)=\left[\begin{array}{cccc}\varepsilon_{11} & \varepsilon_{12} & \cdots & \varepsilon_{1 \mathrm{~m}} \\ \varepsilon_{21} & \varepsilon_{22} & \cdots & \varepsilon_{2 \mathrm{~m}} \\ \vdots & \vdots & \ddots & \vdots \\ \varepsilon_{\mathrm{s} 1} & \varepsilon_{\mathrm{s} 2} & \cdots & \varepsilon_{\mathrm{sm}}\end{array}\right]$,

where the element in the row $i$ is the gray absolute correlation degree between $Y_{i}(i=1,2, \ldots, s)$ and $X_{1}, X_{2}, \ldots, X_{m}$; the element in the column $j$ is the gray absolute correlation degree between $Y_{1}, Y_{2}, \ldots, Y_{s}$ and $X_{j}(j=1,2, \ldots, m)$.

Based on the grey correlation theorem, $\varepsilon_{\mathrm{ij}}$ can be calculated as following:

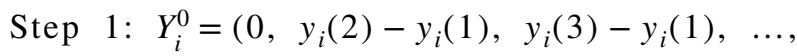

$$
\begin{aligned}
& \left.y_{i}(n)-y_{i}(1)\right) \text {, } \\
& X_{j}^{0}=\left(0, x_{j}(2)-x_{j}(1), x_{j}(3)-x_{j}(1), \ldots, x_{j}(n)-x_{j}(1)\right) \text {. } \\
& \text { S t e p } \quad 2: \quad\left|Y_{i}\right|=\left|\sum_{k=2}^{n-1} y_{i}^{0}(k)+\frac{1}{2} y_{i}^{0}(n)\right| \text {, } \\
& \left|X_{j}\right|=\left|\sum_{k=2}^{n-1} x_{j}^{0}(k)+\frac{1}{2} x_{j}^{0}(n)\right| \text {. } \\
& \text { Step 3: } \varepsilon_{i j}=\frac{1+\left|Y_{s i}\right|+\left|X_{s j}\right|}{1+\left|Y_{s i}\right|+\left|X_{s j}\right|+\left|X_{s j-} Y_{s i}\right|} \text {. }
\end{aligned}
$$

Definition 1 If $\exists l, j \in\{1,2, \ldots, m\}$, and $\varepsilon_{i l} \geq \varepsilon_{i j}, i=1,2, \ldots$, $s$, then, $X_{l}>X_{j}$ (the systemic factors $X_{l}$ is superior to $X_{j}$ ). Further, if $\forall j=1,2, \ldots, m, j \neq l$, and $X_{l}>X_{j}$, then the systemic factors $X_{l}$ can be regarded as the optimal factor.

Definition 2 If $\exists l, j \in\{1,2, \ldots, m\}$, and $\sum_{i=1}^{m} \varepsilon_{i l} \geq \sum_{i=1}^{m} \varepsilon_{i j}$, then, $X_{l} \geq X_{j}$ (the systemic factors $X_{l}$ is better or as good as $\left.X_{j}\right)$.

Definition 3 If $\exists l \in\{1,2, \ldots, \mathrm{m}\}, \forall j=1,2, \ldots, m, j \neq 1$, and $X_{l} \geq X_{j}$, then, $X_{l}$ is the quasi-optimal factor.

\section{Results and discussion}

\section{Effect of ultrasonic-assisted temperature on dye uptake and $K / S$}

Figure 3 shows the dye uptake and $K / S$ of the treated wood specimens against ultrasonic-assisted temperature. With increasing temperature, dye uptake initially increased, and then decreased. As the temperature was raised from 20 to $40{ }^{\circ} \mathrm{C}$, the dye uptake increased by $10.8 \%$. When the temperature got to $40{ }^{\circ} \mathrm{C}$, the dye uptake reached maximum value at $25.5 \%$. This result could be attributed to the high-temperature accelerating molecular thermal motion. 


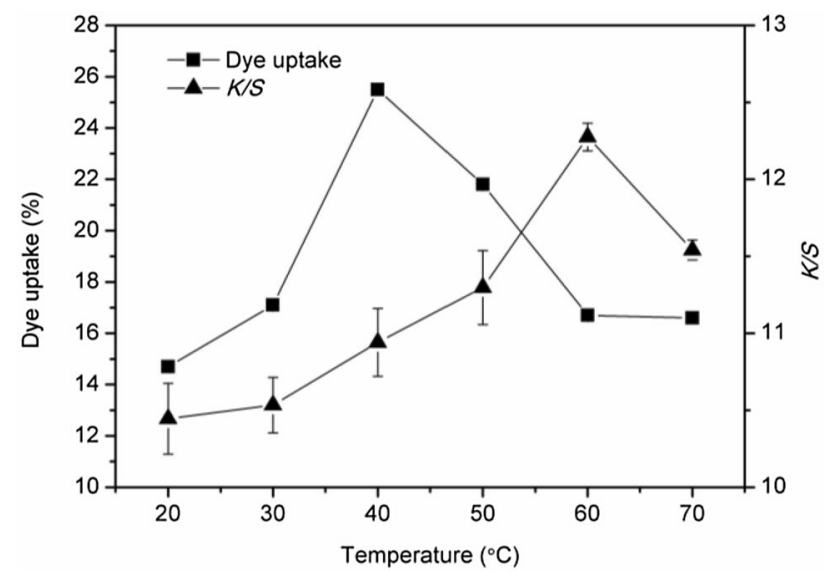

Fig. 3 Effect of ultrasonic-assisted temperature on dye uptake and $K / S$

Moreover, the number of cavitation bubbles formed by ultrasonic vibration reduced due to the irregular movement, resulting in a more homogenous solution [3].

However, when the temperature exceeded $40{ }^{\circ} \mathrm{C}$, dye uptake decreased and then leveled off. The dye used in this study belongs to a low temperature dye; therefore, the molecule activity of dye was reduced by the relatively high temperature of the solution. In addition, the hydrolysis rate of the dye was higher than the rate of its reaction with wood fiber [4]. $K / S$ demonstrates a similar tend between 20 and $70{ }^{\circ} \mathrm{C}$. The maximum $K / S$ value of 12.28 reached at $60{ }^{\circ} \mathrm{C}$, which was slightly higher than the value $(11.30)$ at $50^{\circ} \mathrm{C}$. Obviously, evaluated temperature promoted adsorption and combination between the dye molecules and the surface wood fiber. However, when the temperature was higher than $60{ }^{\circ} \mathrm{C}$, the dye molecules, which reacted with wood fiber, were hydrolyzed.

Higher dye uptake leads to higher utilization rate of dye. Also, higher $K / S$ value results in better dyeing effect. According to the comprehensive analysis, the optimal temperature is $50^{\circ} \mathrm{C}$.

\section{Effect of ultrasonic-assisted dye concentration on dye uptake and $K / S$}

As shown in Fig. 4, when the dye concentration increased from 0.1 to $2.0 \%$, the dye uptake first increased, and then declined. The dye uptake reached its maximum $(29.4 \%)$ at $0.5 \%$ dye concentration. Under the same ultrasonic power, the higher the dye concentration, the greater the dye uptake, which is because the growing number of dye molecules increases the probability of dye penetrating, diffusing, and adsorbing onto the wood. However, further increasing dye concentration, will cause aggregation of the dye molecules and therefore decrease dye uptake.

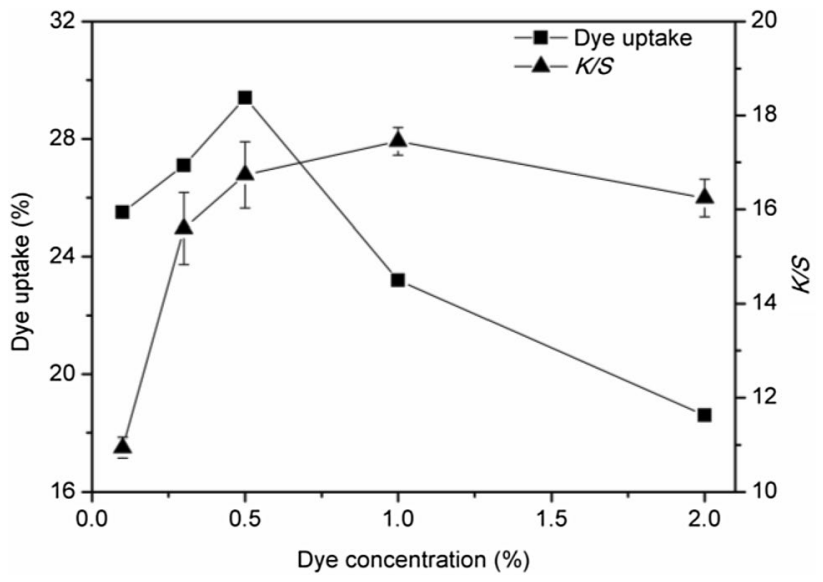

Fig. 4 Effect of ultrasonic-assisted dye concentration on dye uptake and $K / S$

$K / S$ value has a tendency to increase with increasing dye concentrations. The $K / S$ increased greatly from 10.94 at dye concentration of $0.1 \%$ to 17.45 at $1.0 \%$. With increasing dye concentration, the number of dye molecules increased per unit volume [27]. Thus, the number of dye molecules absorbed on per unit area of the wood surface increased and the $K / S$ value improved.

Considering both factors of dye uptake and $K / S$, the ideal dye concentration is $0.5 \%$. At that dye concentration, the dye uptake was $29.4 \%$ and $K / S$ value was 16.74 .

\section{Effect of ultrasonic-assisted power on dye uptake and $K / S$}

Figure 5 shows that dye uptake increased with increased ultrasonic power. Compared to wood samples without application of ultrasonic power, dye uptake significantly increased with sonication. A higher ultrasonic power

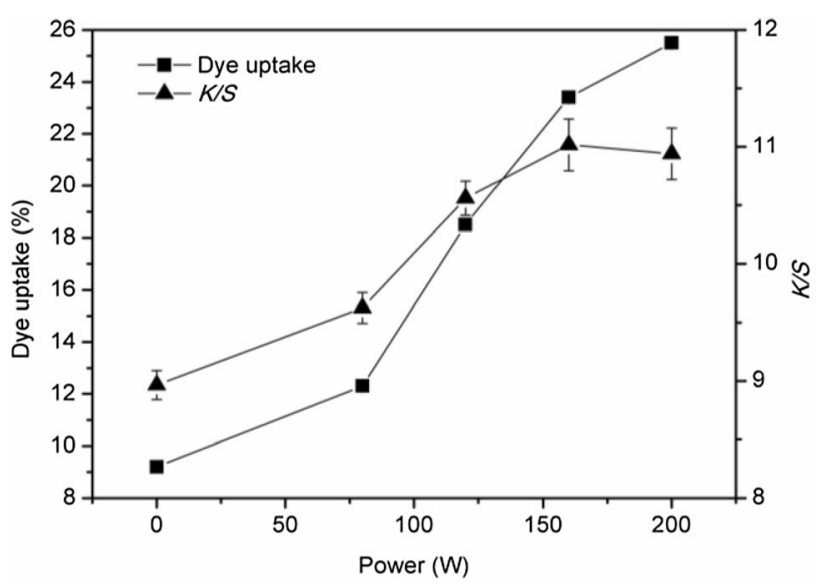

Fig. 5 Effect of ultrasonic-assisted power on dye uptake and $K / S$ 
resulted in a higher dye uptake. When $200 \mathrm{~W}$ of ultrasonic power was applied, the dye uptake was maximized to $25.5 \%$. Higher ultrasonic power could improve the permeability of the wood, allowing more dye molecules to penetrate wood and enhancing dye uptake. Moreover, an improvement in the ultrasonic power could contribute to promoting the activation of the dye molecules, which gave rise to a higher proliferation potential.

$K / S$ value increased at first and then decreased slightly as ultrasonic power increased. The $K / S$ peaked at 11.02 with an ultrasonic power of $160 \mathrm{~W}$. This behavior could be attributed to the assisting effect of ultrasonic power on the dyeability of wood fiber with Reactive Brilliant Blue KN-R dye. The ultrasound has threefold effects (dispersion, degassing and diffusion) on the dyeing system. First, ultrasonic vibration cavitation produces uniform dispersions in the dye bath. Second, dissolved or entrapped air molecules are expelled from fiber capillaries and interstices at the crossover of fabric into liquid by cavitation, thus facilitating dye-fiber contact. Third, the rate of diffusion of the dye inside the fiber and the chemical reaction between dye and fiber are also accelerated by piercing the insulating layer covering the fiber [28-31]. From the viewpoint of efficiency and cost, the optimal power for dye uptake and $K / S$ is $160 \mathrm{~W}$.

\section{Effect of ultrasonic-assisted dipping time on dye uptake and $K / S$}

The effects of dyeing time on dye uptake and $K / S$ are illustrated in Fig. 6. Dye uptake rapidly increased from 11.5 to $25.5 \%$ with prolonged dipping time, and then decreased slightly after $120 \mathrm{~min}$. This phenomenon may be due to the fact that wood dyeing process is a dynamic sorption and desorption equilibrium process for dye molecules to diffuse and infiltrate the internal structure of wood [32]. In addition, the cavitation and thermal effect generated by ultrasonic

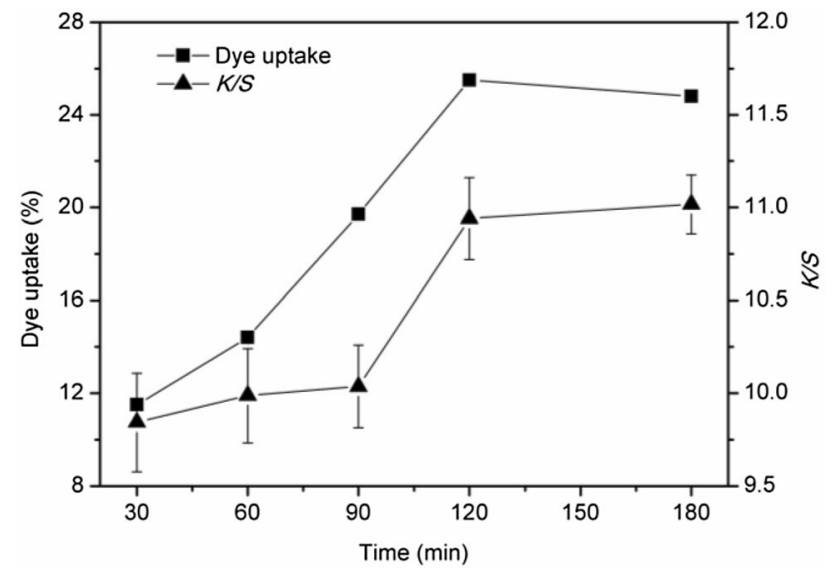

Fig. 6 Effect of ultrasonic-assisted dyeing time on dye uptake and $K / S$ waves are also beneficial to the sorption process of dye molecules into the wood. However, the ultrasonic treatment could accelerate the dissolution of extractives within wood. Moreover, with extended time, more dye molecules permeating wood, thus reducing the concentration difference of dye liquid inside wood tissues. Also, the dye molecules had the traces of hydrolysis. All the three factors mentioned above led to the slightly decrease of dye uptake.

$K / S$ value obtained increased as time increased. The peak (11.02) was attained after $180 \mathrm{~min}$ of dipping time. With prolongation of dyeing time, the wood fibers had enough time to take up dye molecules and further reacted with them. As the time further increased, the effective flow area of dye solution is smaller due to the triangle adsorption principle of the dye molecules [33]. After 120 min of dyeing, the reaction between wood fibers and dye molecules was almost completed, so the $K / S$ changed a little. Therefore, based on comprehensive consideration, the optimal dyeing time is $120 \mathrm{~min}$.

\section{Effect of ultrasonic-assisted dyeing assistant on dye uptake and $K / S$}

Figure 7 shows the effect of dyeing assistant on the dye uptake and $K / S$. The dye uptake firstly increased rapidly from 16.7 to $25.5 \%$, and then gradually increased to $28.9 \%$. When the dyeing assistant was up to $50 \mathrm{~g} / \mathrm{L}$, the dye uptake decreased to $22.4 \%$. During the dyeing process, the sodium chloride electrolyte could reduce the repulsive force between chromophores of dye and fiber surfaces, and promote the combination of dye molecules and wood fiber. Moreover, with elevated addition of dyeing assistant, the sodium ion concentration increased, and thus improved the activity of reactive dyes. However, the excessive sodium ion might have

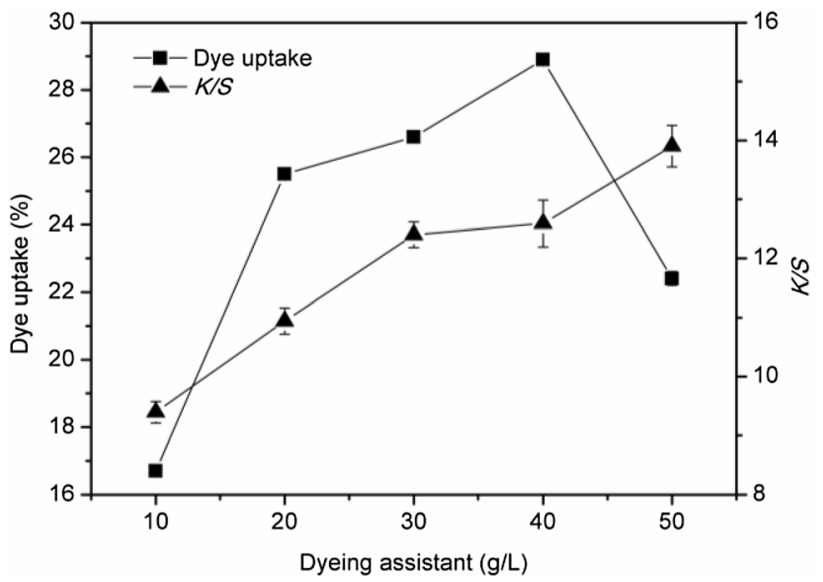

Fig. 7 Effect of ultrasonic-assisted dyeing assistant on dye uptake and $K / S$ 
led to the aggregation and even desorption of the dye molecules, so the dye uptake decreased.

$K / S$ value always increased with increased dyeing assistant. The $K / S$ value reached a maximum (13.90) when the dyeing assistant was $50 \mathrm{~g} / \mathrm{L}$. Sodium chloride, which belongs to neutral electrolyte, plays an important role in the dyeing process as the leveling agent and dyeing assistant. Therefore, the dye molecules could better adsorb and combine with the wood surface. Besides, the ultrasonic power helps better dyeing in the presence of salt [34]. According to Fig. 7, the optimal dyeing assistant was determined to be $40 \mathrm{~g} / \mathrm{L}$.

\section{Effect of ultrasonic-assisted dye-fixing agent on dye uptake and $K / S$}

The alkaline agent selected as fixing agent could enhance dye uptake [35]. Different amount of fixing agent was added, and the results of its effects are presented in Fig. 8. Clearly, dye uptake and $K / S$ value initially increased, and then decreased with increased fixing agent. Dye uptake reached the maximum value at $31.2 \%$, when the fixing agent was increased to $25 \mathrm{~g} / \mathrm{L}$. However, the $K / S$ was maximized to 13.00 at $30 \mathrm{~g} / \mathrm{L}$. Addition of fixing agent could increase the $\mathrm{pH}$ value of dye solution and form more cellulose hydroxy anions, and thus the rate of dye-fixing reaction was accelerated. Moreover, the amount of dye fixed on the wood fiber rapidly increased, so the $K / S$ value increased. However, when addition of fixing agent was further increased, the hydrolysis rate was higher than the reaction rate, so the dye uptake and $K / S$ decreased. Therefore, according to the comprehensive consideration, the better fixing agent was $25 \mathrm{~g} / \mathrm{L}$.

Through the above analyses, the idealized process by single-factor experiment uses a temperature of $50{ }^{\circ} \mathrm{C}$, a dye concentration of $0.5 \%$, a ultrasonic power of $160 \mathrm{~W}$, a dyeing time of $120 \mathrm{~min}$, a dyeing assistant of $40 \mathrm{~g} / \mathrm{L}$, and a fixing agent of $25 \mathrm{~g} / \mathrm{L}$.

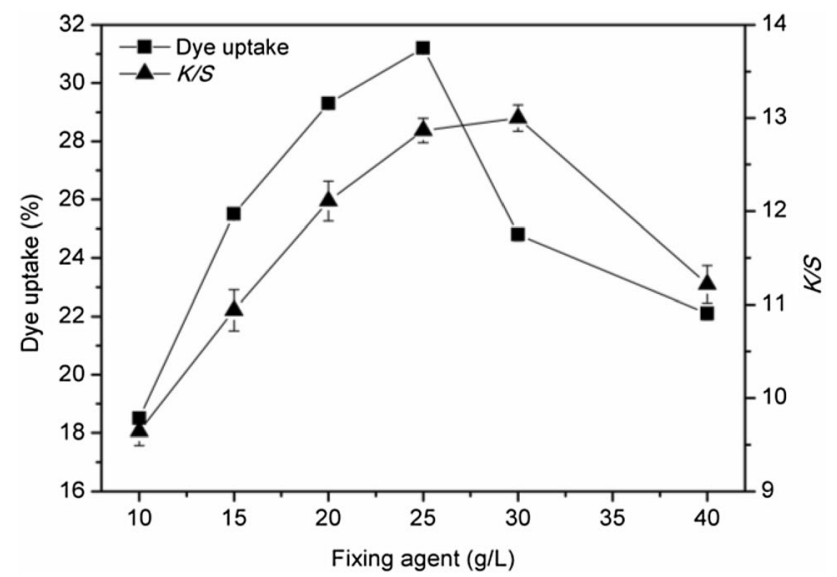

Fig. 8 Effect of ultrasonic-assisted fixing agent on dye uptake and $K / S$

\section{Grey system theory analysis}

We assume dye uptake $\left(Y_{1}\right)$ and $K / S\left(Y_{2}\right)$ as the evaluation sequence, and temperature $\left(X_{1}\right)$, dye concentration $\left(X_{2}\right)$, ultrasonic power $\left(X_{3}\right)$, dipping time $\left(X_{4}\right)$, dyeing assistant $\left(X_{5}\right)$, and dye-fixing agent $\left(X_{6}\right)$ as related sequence factors. Table 2 shows the detailed numerical value of systematic characteristics behavior sequences $(Y)$ and correlation factor behavior sequences $(X)$.

We calculated the grey absolute correlation degree of $Y_{1}$ and $Y_{2}$ with $X_{1}, X_{2}, X_{3}, X_{4}, X_{5}$ and $X_{6}$ by the three steps, respectively, and then obtained the gray absolute correlation matrix as follows:

$$
\begin{aligned}
A & =\left[\begin{array}{llllll}
\varepsilon_{11} & \varepsilon_{12} & \varepsilon_{13} & \varepsilon_{14} & \varepsilon_{15} & \varepsilon_{16} \\
\varepsilon_{21} & \varepsilon_{22} & \varepsilon_{23} & \varepsilon_{24} & \varepsilon_{25} & \varepsilon_{26}
\end{array}\right] \\
& =\left[\begin{array}{llllll}
0.5020 & 0.5995 & 0.5030 & 0.5111 & 0.5266 & 0.5353 \\
0.5007 & 0.7920 & 0.5010 & 0.5038 & 0.5091 & 0.5120
\end{array}\right] .
\end{aligned}
$$

Obviously, $\varepsilon_{i 2}>\varepsilon_{i 6}>\varepsilon_{i 5}>\varepsilon_{i 4}>\varepsilon_{i 3}>\varepsilon_{i 1}(i=1,2)$, namely, $X_{2}>X_{6}>X_{5}>X_{4}>X_{3}>X_{1}$, meets the Definition 1. It means that dye concentration $\left(X_{2}\right)$ had the strongest effect on dye uptake $\left(Y_{1}\right)$ and $K / S\left(Y_{2}\right)$, and temperature $\left(X_{1}\right)$ had the weakest effect on dye uptake $\left(Y_{1}\right)$ and $K / S\left(Y_{2}\right)$ among these factors. Therefore, this assessment method helps to provide a theoretical reference for ultrasonic-assisted wood dyeing techniques, and the producer could better control the dyeing technology in the actual production.

\section{FTIR analysis}

The FTIR spectra of wood samples in the $4000-400 \mathrm{~cm}^{-1}$ region are shown in Fig. 9. The broad peak that occurs at $3400-3200 \mathrm{~cm}^{-1}$ was associated with $-\mathrm{OH}$ stretching in hydroxyl groups originating mainly from cellulose [36]. The absorption at $1740 \mathrm{~cm}^{-1}$ was due to $\mathrm{C}=\mathrm{O}$ stretching of xylan [37]. The peak at $1034 \mathrm{~cm}^{-1}$ was attributed to $\mathrm{C}-\mathrm{O}-\mathrm{C}$ stretching of aliphatic ether bond [4]. In comparison with the undyed wood, the $-\mathrm{OH}$ band was broader in the case of dyed wood, which could be caused by different types of inter- and intramolecular hydrogen bonds [38, 39]. Besides, the $1740 \mathrm{~cm}^{-1}$ band declined clearly after the conventional dyeing treatment, suggesting the degradation of hemicellulose [40]. However, the $\mathrm{C}=\mathrm{O}$ stretching vibration of ultrasonic-assisted dyeing treatment declined more than that of the conventional dyeing treatment, which may be attributed to the cavitation and thermal effects of the ultrasonic waves. The absorbance ratio of $1034 \mathrm{~cm}^{-1}$ was increased after dyeing treatment, indicating the formation of ether bond, which may result from the reaction between wood component and the dye. 
Table 2 The values of systematic characteristics behavior sequences $(Y)$ and correlation factor behavior sequences $(X)$

\begin{tabular}{|c|c|c|c|c|c|c|c|}
\hline$Y_{1}(\%)$ & $Y_{2}$ & $X_{1}$ & $X_{2}(\%)$ & $X_{3}$ & $X_{4}$ & $X_{5}$ & $X_{6}$ \\
\hline 14.7 & 10.44 & 20 & 0.1 & 200 & 120 & 20 & 15 \\
\hline 17.1 & 10.53 & 30 & 0.1 & 200 & 120 & 20 & 15 \\
\hline 25.5 & 10.94 & 40 & 0.1 & 200 & 120 & 20 & 15 \\
\hline 21.8 & 11.30 & 50 & 0.1 & 200 & 120 & 20 & 15 \\
\hline 16.7 & 12.28 & 60 & 0.1 & 200 & 120 & 20 & 15 \\
\hline 16.6 & 11.54 & 70 & 0.1 & 200 & 120 & 20 & 15 \\
\hline 25.5 & 10.94 & 40 & 0.1 & 200 & 120 & 20 & 15 \\
\hline 27.1 & 15.60 & 40 & 0.3 & 200 & 120 & 20 & 15 \\
\hline 29.4 & 16.74 & 40 & 0.5 & 200 & 120 & 20 & 15 \\
\hline 23.2 & 17.45 & 40 & 1.0 & 200 & 120 & 20 & 15 \\
\hline 18.6 & 16.24 & 40 & 2.0 & 200 & 120 & 20 & 15 \\
\hline 9.2 & 8.97 & 40 & 0.1 & 0 & 120 & 20 & 15 \\
\hline 12.3 & 9.62 & 40 & 0.1 & 80 & 120 & 20 & 15 \\
\hline 18.5 & 10.56 & 40 & 0.1 & 120 & 120 & 20 & 15 \\
\hline 23.4 & 11.02 & 40 & 0.1 & 160 & 120 & 20 & 15 \\
\hline 25.5 & 10.94 & 40 & 0.1 & 200 & 120 & 20 & 15 \\
\hline 11.5 & 9.84 & 40 & 0.1 & 200 & 30 & 20 & 15 \\
\hline 14.4 & 9.99 & 40 & 0.1 & 200 & 60 & 20 & 15 \\
\hline 19.7 & 10.04 & 40 & 0.1 & 200 & 90 & 20 & 15 \\
\hline 25.5 & 10.94 & 40 & 0.1 & 200 & 120 & 20 & 15 \\
\hline 24.8 & 11.02 & 40 & 0.1 & 200 & 180 & 20 & 15 \\
\hline 16.7 & 9.39 & 40 & 0.1 & 200 & 120 & 10 & 15 \\
\hline 25.5 & 10.94 & 40 & 0.1 & 200 & 120 & 20 & 15 \\
\hline 26.6 & 12.40 & 40 & 0.1 & 200 & 120 & 30 & 15 \\
\hline 28.9 & 12.59 & 40 & 0.1 & 200 & 120 & 40 & 15 \\
\hline 22.4 & 13.90 & 40 & 0.1 & 200 & 120 & 50 & 15 \\
\hline 18.5 & 9.64 & 40 & 0.1 & 200 & 120 & 20 & 10 \\
\hline 25.5 & 10.94 & 40 & 0.1 & 200 & 120 & 20 & 15 \\
\hline 29.3 & 12.11 & 40 & 0.1 & 200 & 120 & 20 & 20 \\
\hline 31.2 & 12.87 & 40 & 0.1 & 200 & 120 & 20 & 25 \\
\hline 24.8 & 13.00 & 40 & 0.1 & 200 & 120 & 20 & 30 \\
\hline 22.1 & 11.22 & 40 & 0.1 & 200 & 120 & 20 & 40 \\
\hline
\end{tabular}

\section{TG analysis}

Thermal stability of the undyed and dyed wood samples was studied using TG. Figure 10 shows the mass loss and differential TG (DTG) curves of the samples ranging from room temperature to $600{ }^{\circ} \mathrm{C}$. For the undyed wood, the first degradation region from 50 to $120{ }^{\circ} \mathrm{C}$ relates to the release of moisture and adsorbed water from the wood [41].The dyed wood had a similar tendency to undyed wood at this stage. The thermal degradation patterns reveal that most of the degradation events occur between 200 and $400{ }^{\circ} \mathrm{C}$, which is consistent with a previous study [42]. At this stage, the residue of undyed wood was $6.52 \%$, while the residues of the conventional dyed wood and ultrasonic-assisted dyed wood were $11.27 \%$ and $13.23 \%$, respectively (Table 3). This result can be attributed the dye used in this study reacting with wood component and generating strong ester bond.
In addition, due to the assisting effect of ultrasonic power on the dyeability of wood fiber, more ester bonds could be formed and thus increased the thermal stability. Additionally, as can be seen from Fig. 10 and Table 3, the temperature at maximum degradation rate changed obviously. The temperature at the maximum degradation rate of undyed wood was $350{ }^{\circ} \mathrm{C}$, while the temperature at the maximum degradation rate of dyed wood were $297{ }^{\circ} \mathrm{C}$ and $287{ }^{\circ} \mathrm{C}$, separately, indicating the dye had a chemical reaction with the wood component.

\section{XRD analysis}

Appearing in Fig. 11 are XRD spectra of undyed and dyed wood. The characteristic peaks of poplar wood are at $2 \theta=16.0^{\circ}, 22.0^{\circ}$, and $34.6^{\circ}$, corresponding to the crystal plane diffraction peaks of (101), (002), and (040) in 


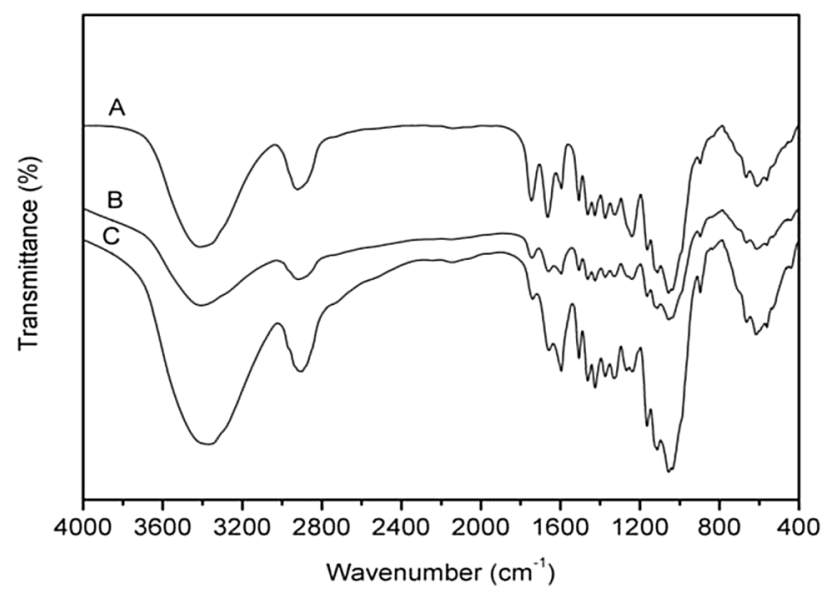

Fig. 9 FTIR spectra of A undyed, B dyed at $50{ }^{\circ} \mathrm{C}, 0.5 \%$ dye concentration, $120 \mathrm{~min}$ dyeing time, $40 \mathrm{~g} / \mathrm{L}$ dyeing assistant, $25 \mathrm{~g} / \mathrm{L}$ fixing agent, and $\mathrm{C}$ dyed at $50{ }^{\circ} \mathrm{C}, 0.5 \%$ dye concentration, $120 \mathrm{~min}$ dyeing time, $40 \mathrm{~g} / \mathrm{L}$ dyeing assistant, $25 \mathrm{~g} / \mathrm{L}$ fixing agent, and $160 \mathrm{~W}$ ultrasonic power

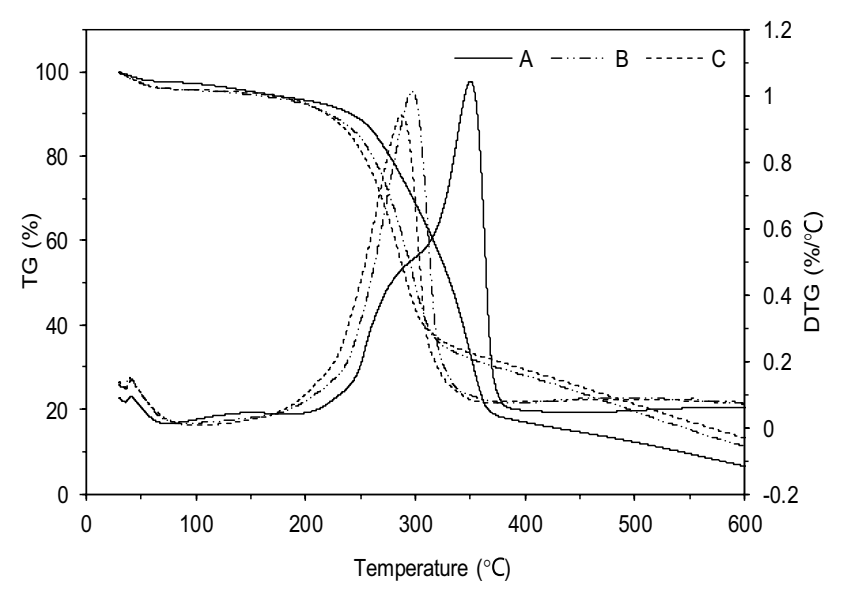

Fig. 10 TG and DTG patterns of A undyed, B dyed at $50{ }^{\circ} \mathrm{C}, 0.5 \%$ dye concentration, $120 \mathrm{~min}$ dyeing time, $40 \mathrm{~g} / \mathrm{L}$ dyeing assistant, $25 \mathrm{~g} / \mathrm{L}$ fixing agent, and $\mathrm{C}$ dyed at $50{ }^{\circ} \mathrm{C}, 0.5 \%$ dye concentration, $120 \mathrm{~min}$ dyeing time, $40 \mathrm{~g} / \mathrm{L}$ dyeing assistant, $25 \mathrm{~g} / \mathrm{L}$ fixing agent, and $160 \mathrm{~W}$ ultrasonic power

Table 3 Thermogravimetric parameters for thermal degradation of undyed and dyed wood veneer

\begin{tabular}{llc}
\hline Sample & $T_{\max 1}\left({ }^{\circ} \mathrm{C}\right)^{\mathrm{a}}$ & Residue $(\%)^{\mathrm{b}}$ \\
\hline Undyed wood veneer & 350 & 6.52 \\
$\begin{array}{l}\text { Dyed wood veneer with } \\
\quad \text { conventional treatment }\end{array}$ & 297 & 11.27 \\
$\begin{array}{l}\text { Dyed wood veneer with } \\
\text { ultrasonic-assisted treatment }\end{array}$ & 287 & 13.23 \\
\hline
\end{tabular}

${ }^{\mathrm{a}}$ Temperature at maximum degradation rate

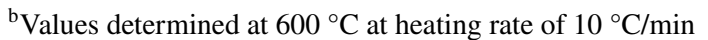

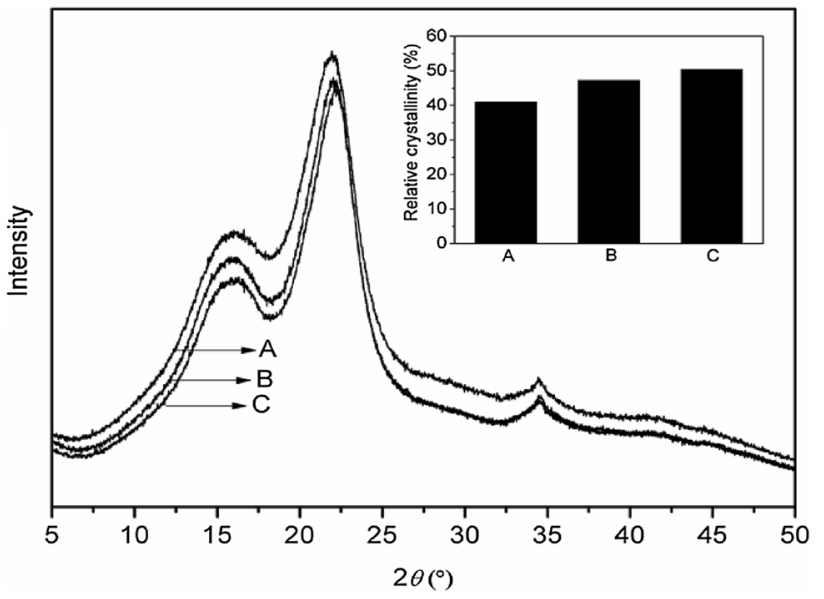

Fig. 11 XRD curves and relative crystallinity of A undyed, B dyed at $50{ }^{\circ} \mathrm{C}, 0.5 \%$ dye concentration, $120 \mathrm{~min}$ dyeing time, $40 \mathrm{~g} / \mathrm{L}$ dyeing assistant, $25 \mathrm{~g} / \mathrm{L}$ fixing agent, and $\mathrm{C}$ dyed at $50{ }^{\circ} \mathrm{C}, 0.5 \%$ dye concentration, $120 \mathrm{~min}$ dyeing time, $40 \mathrm{~g} / \mathrm{L}$ dyeing assistant, $25 \mathrm{~g} / \mathrm{L}$ fixing agent, and $160 \mathrm{~W}$ ultrasonic power

cellulose, respectively. The position of the peaks did not change, indicating that the main crystalline structure of wood was not distinctly influenced by dyeing. The crystallinity of undyed wood was $41.05 \%$, while the conventional dyed wood and ultrasonic-assisted dyed wood were $47.36 \%$ and $50.52 \%$, respectively. The increased crystallinity of conventional dyed wood is attributed to the hydrothermal dying process. Compared with the conventional dyed wood, the crystallinity of the ultrasonic-assisted dyed wood increased. The increased crystallinity may be ascribed to the degradation caused by acoustic cavitation, which reduces the amorphous fractions of wood, and enriches the relative crystalline content [43].

\section{SEM analysis}

The SEM results are shown in Fig. 12. Empty cell walls and pits were obviously observed in the undyed wood (Fig. 12A), while these empty places were filled with a certain amount of dye molecules (Fig. 12B, C). Compared with the undyed and conventional dyed wood, apparently, the wood vessel walls of ultrasonic-assisted dyed wood appear rough (Fig. 12C). The ultrasonic cavitation and heat effects resulted in sharp moisture vaporization in the wood cell cavity, which caused an outward diffusion of vapor pressure to act on the wood vessel cell wall. This led to some pit membranes to rupture, forming new channels for dye liquor, which increased the dyeability of wood. 

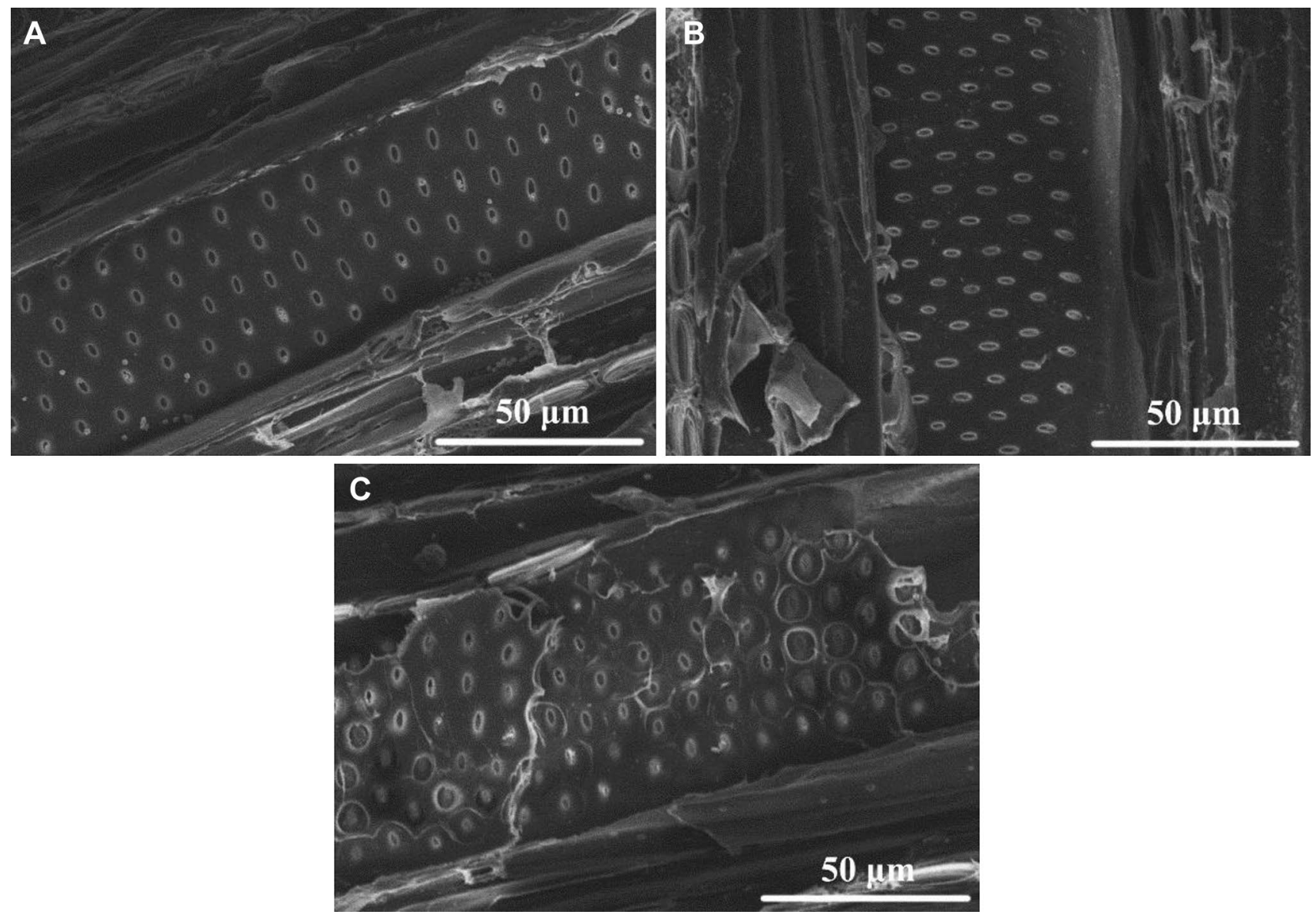

Fig. 12 Scanning electron micrographs: A undyed, B dyed at $50{ }^{\circ} \mathrm{C}$, $0.5 \%$ dye concentration, $120 \mathrm{~min}$ dyeing time, $40 \mathrm{~g} / \mathrm{L}$ dyeing assistant, $25 \mathrm{~g} / \mathrm{L}$ fixing agent, and $\mathbf{C}$ dyed at $50{ }^{\circ} \mathrm{C}, 0.5 \%$ dye concentra-

\section{Conclusions}

Ultrasonic-assisted dyeing as an environment-friendly and energy-efficient wood dyeing method improved the decorative property of fast-growing poplar wood.

Different ultrasonic-assisted factors affected dye uptake and $K / S$ in different ways. The idealized process by a singlefactor experiment in this study used a temperature of $50{ }^{\circ} \mathrm{C}$, a dye concentration of $0.5 \%$, a ultrasonic power of $160 \mathrm{~W}$, a dyeing time of $120 \mathrm{~min}$, a dyeing assistant of $40 \mathrm{~g} / \mathrm{L}$, and a fixing agent of $25 \mathrm{~g} / \mathrm{L}$.

Through the grey system theory analysis, dye concentration had the strongest effect on dye uptake and $K / S$, while temperature had the weakest effect on dye uptake and $K / S$ among these factors.

The reactive dye used in the study had chemical reaction with wood component, and formed ester groups. After the ultrasonic-assisted dyeing, the thermal stability and crystallinity of fast-growing poplar wood samples were both increased. Moreover, the dye molecules diffused into the cell tion, $120 \mathrm{~min}$ dyeing time, $40 \mathrm{~g} / \mathrm{L}$ dyeing assistant, $25 \mathrm{~g} / \mathrm{L}$ fixing agent, and $160 \mathrm{~W}$ ultrasonic power

cavity, wood vessel, aperture, and part of the wood microstructure such as pit membrane was mechanically damaged, creating new fluid channels for the dye and increasing the dyeability of wood.

Acknowledgements This work was supported by Fundamental Research Funds for the Central Universities (no. 2016ZCQ01).

\section{Compliance with ethical standards}

Conflict of interest The authors declare that there is no conflict of interest regarding the publication of this paper.

\section{References}

1. Ayrilmis N, Kaymakci A (2013) Fast growing biomass as reinforcing filler in thermoplastic composites: Paulownia elongate wood. Ind Crop Prod 43:457-464

2. Dong Y, Yan Y, Wang K, Li J, Zhang S, Xia C, Shi SQ, Cai L (2016) Improvement of water resistance, dimensional stability, 
and mechanical properties of poplar wood by rosin impregnation. Eur J Wood Prod 74:177-184

3. Liu Y, Hu JH, Gao JM, Guo HW, Chen Y, Cheng QZ, Brian KV (2015) Wood veneer dyeing enhancement by ultrasonic-assisted treatment. Bioresources 10:1198-1212

4. Hu JH, Li Y, Liu Y, Guo HW, Li L (2016) Evaluation of the dyeing properties of basswood veneer treated by dichlorotriazine reactive dye based on gray correlation analysis. Bioresources 11:66-481

5. Arai K, Nakajima K (2011) Ribbon-like variegation of Pinus radiata using the adsorption on basic dyes in the capillary penetration process IV. Dyeing wood in parallel colored strips through the process of capillary penetration (in Japanese). Mokuzai Gakkaishi 57:34-41

6. Sun D, Yu X (2011) Ultrasonic-assisted dyeing of poplar veneer. Wood Fiber Sci 43:442-448

7. Zhao Y, Tan X, Yuan Y, Yu Z, Tang J (2014) Dyeing of acetylated wood with disperse dye. Wood Fiber Sci 46:1-11

8. Parvinzadeh M, Memari N, Shaver M, Katozian B, Ahmadi S, Ziadi I (2010) Influence of ultrasonic waves on the processing of cotton with cationic softener. J Surfactants Deterg 13:135-141

9. Zhuang QC (2014) Engineered wood-reconstituted decorative lumber. China Forestry Publishing House, Beijing

10. Rowell RM (2012) Handbook of wood chemistry and wood composites, 2nd edn. CRC Press, Boca Raton

11. Shao J, Liua J, Carr CM (2001) Investigation into the synergistic effect between uv/ozone exposure and peroxide pad-batch bleaching on the printability of wool. Color Technol 117:270-275

12. Gogate PR (2008) Cavitational reactors for process intensification of chemical processing applications: a critical review. Chem Eng Process 47:515-527

13. Atav R, Yurdakul A (2016) Ultrasonic assisted dyeing of angora fibre. Fibres Text East Eur 5:137-142

14. Kamel MM, El-Shishtawy RM, Yussef BM (2005) Ultrasonic assisted dyeing III. Dyeing of wool with lac as a natural dye. Dyes Pigments 65:103-110

15. Suslick KS, Hammerton DA, Cline RE (1986) Sonochemical hot spot. J Am Chem Soc 108:5641-5642

16. Keun WL, Jae PK (2001) Effect of ultrasound on disperse dye particle size. Text Res J 71:395-398

17. Abou-Okeil A, El-Shafie A, El Zawahry MM (2010) Ecofriendly laccase hydrogen peroxide/ultrasound-assisted bleaching of linen fabrics and its influence on dyeing efficiency. Ultrason Sonochem 17:383-390

18. Guesmi A, Ladhari N, Sakli F (2013) Ultrasonic preparation of cationic cotton and its application in ultrasonic natural dyeing. Ultrason Sonochem 20:571-579

19. Vouters M, Rumeau P, Tierce P, Costes S (2004) Ultrasounds: an industrial solution to optimise costs, environmental requests and quality for textile finishing. Ultrason Sonochem 11:33-38

20. Ma J, Chen S, Liu C, Xu W, Wang S (2008) The influences of ultrasonic on embedding nanoparticles into porous fabric materials. Appl Acoust 9:763-769

21. Tanaka T, Avramidis S, Shida S (2010) A preliminary study on ultrasonic treatments effect on transverse wood permeability. Maderas-Cienc Tecnol 12:3-9

22. He Z, Yang F, Peng Y, Yi S (2013) Ultrasonic-assisted vacuum drying of wood: Effect on drying time and product quality. Bioresources 8:855-863

23. He Z, Zhao Z, Yang F, Yi S (2014) Effect of ultrasound pretreatment on wood prior to vacuum drying. Maderas-Cienc Tecnol $16: 395-402$
24. Li Y, Liu Y, Chen W, Wang Q, Liu Y, Yu H (2015) Facile extraction of cellulose nanocrystals from wood using ethanol and peroxide solvothermal pretreatment followed by ultrasonic nanofibrillation. Green Chem 18:1010-1018

25. Wang X, Wang F, Yu Z, Zhang Y, Qi C, Du L (2017) Surface free energy and dynamic wettability of wood simultaneously treated with acidic dye and flame retardant. J Wood Sci 63:271-280

26. Shen JG, Li Y, He J (2016) On the Kubelka-Munk absorption coefficient. Dyes Pigments 127:187-188

27. Sun J, Liu YP, Yu YX, Fang WJ (2012) Research on the effect of dyeing process on the dye-uptake of eucalyptus. Pract For Technol 12:76-77

28. Lorimer JP, Mason TJ, Plattes M, Phull SS (2000) Dye effluent decolourisation using ultrasonically assisted electro-oxidation. Ultrason Sonochem 7:237-242

29. Kamel MM, El-Shishtawy RM, Hanna HL, Ahmed NSE (2003) Ultrasonic-assisted dyeing: I. Nylon dyeability with reactive dyes. Polym Int 52:373-380

30. Merdan N, Akalin M, Kocak D, Usta I (2004) Effects of ultrasonic energy on dyeing of polyamide (microfibre)/Lycra blends. Ultrasonics 42:165-168

31. Kamel MM, El-Shishtawy RM, Youssef BM, Mashaly H (2007) Ultrasonic assisted dyeing. IV. Dyeing of cationised cotton with lac natural dye. Dyes Pigments 73:279-284

32. Yu ZM, Zhao L, Li WJ (2002) Study on permeable mechanism with dyes during wood dyeing. J Beijing For Univ 24:79-82

33. Wu XF, Yu ZM, Zhang Y (2014) Dyeing property of xylem utilizing the axil direction of freshly-felled Populus cathayana. J Beijing For Univ 36:125-129

34. Kamel MM, El-Shishtawy RM, Youssef BM, Mashaly H (2005) Ultrasonic assisted dyeing III. Dyeing of wool with lac as a natural dye. Dyes Pigments 65:103-110

35. Hu J, Fan W, Luo B, Guo H, Li L (2016) Assessment of the dyeing properties of maple veneer treated by dichlorotriazine reactive dye based on fuzzy comprehensive evaluation. Wood Res 61:719-732

36. Yan Y, Dong Y, Li C, Chen H, Zhang S, Li J (2015) Optimization of reaction parameters and characterization of glyoxal-treated poplar sapwood. Wood Sci Technol 49:241-256

37. Chu D, Mu J, Zhang L, Li Y (2016) Promotion effect of NP fire retardant pretreatment on heat-treated poplar wood. Part 2: hygroscopicity, leaching resistance, and thermal stability. Holzforschung 71:1-9

38. Sugiyama J, Persson J, Chanzy H (1991) Combined infrared and electron diffraction study of the polymorphism of native cellulose. Macromolecules 24:2461-2466

39. Popescu MC, Froidevaux J, Navi P, Popescu CM (2013) Structural modifications of Tilia cordata wood during heat treatment investigated by FT-IR and 2D IR correlation spectroscopy. J Mol Struct 1033:176-186

40. Xiao Z, Xie Y, Adamopoulos S, Mai C (2012) Effect of chemical modification with glutaraldehyde on the weathering performance of Scots pine sapwood. Wood Sci Technol 46:749-767

41. Wang X, Zhang Y, Yu Z, Qi C (2016) Properties of fast-growing poplar wood simultaneously treated with dye and flame retardant. Eur J Wood Prod 75:325-333

42. Dong Y, Yan Y, Zhang S, Li J (2014) Wood/polymer nanocomposites prepared by impregnation with furfuryl alcohol and nano$\mathrm{SiO}_{2}$. Bioresources 9:6028-6040

43. Qiu S, Wang Z, He Z, Yi S (2016) The effect of ultrasound pretreatment on poplar wood dimensional stability. Bioresources 11:7811-7821 